\title{
MANUAIS DIDÁTICOS COMO PATRIMÔNIO HISTÓRICO-EDUCATIVO: ARTEFATOS DA CULTURA MATERIAL ESCOLAR ${ }^{1}$
}

\author{
DIDACTIC MANUALS AS HISTORICAL-EDUCATIONAL \\ PATRIMONY: SCHOOL MATERIAL CULTURE ARTEFACTS
}

\section{MANUALES DIDÁCTICOS COMO PATRIMONIO HISTÓRICO- EDUCATIVO: ARTEFACTOS DE LA CULTURA MATERIAL ESCOLAR}

\author{
Maristela da Rosa* \\ Pesquisadora da Universidade do Estado de Santa Catarina \\ Gladys Mary Ghizoni Teive** \\ Membro da Associação Nacional de Pós-Graduação em Educação (ANPEd); \\ Pesquisadora associada do Centro de Investigación MANES, Universidad Nacional \\ de Educación a Distancia de Madri.
}

Resumo: Neste artigo objetivou-se cogitar o potencial do estudo histórico da cultura material escolar. Entre os artefatos escolares, tomaram-se os manuais didáticos - objetos indiciários que materializam concepções pedagógicas, saberes e práticas - como exemplares de uma cultura escolar. Na primeira parte aborda-se a cultura material escolar como um conjunto de documentos/fontes que contribuem para o desnudamento da "caixa preta" da escola e a necessidade de salvaguardá-los como exemplares do patrimônio histórico-educativo; na segunda parte tratam-se dos manuais didáticos como objetos-huella que, entrecruzados com outras fontes, podem trazer indícios sobre o funcionamento interno da escola. Por fim, apresentam-se dois manuais didáticos e as alternativas de pesquisa histórica que deles advêm.

Palavras-chave: História da educação. Manuais didáticos. Patrimônio histórico-educativo. Cultura material escolar.

\footnotetext{
" Mestre em Educação pela Universidade do Estado de Santa Catarina; doutoranda no Programa de Pós Graduação Doutorado em Educação na Linha de História e Historiografia da Educação na Universidade do Estado de Santa Catarina.

${ }^{*}$ Doutora em Educação pela Universidade Federal do Paraná; Mestre em Educação pela Universidade Federal de Santa Catarina.
} 
Abstract: In this article one aimed to discuss the potential of historical studies of school material culture. Among the school artefacts, the didactic manuals - evidentiary objects that matter pedagogical conceptions, knowledge and practices - were taken as models of a school culture. In the first part of this article it is discussed the school material culture as a group of documents/sources that contributes to show the school's "black box" and the need of keeping it safe as a model of the historical-educational patrimony. The second part deals with the didactic manuals as huella-objects that, intercrossed with other sources, can provide clues about the school's inner workings. Finally, two didactic manuals and their historical research options are shown. Keywords: Education history. Didactic manuals. Historical-educational patrimony. School material culture.

Resumen: El artículo pretende contemplar el potencial del estudio histórico de la cultura material de la escuela. Entre los artefactos escolares, se toman los manuales didácticos -objetos indiciarios que materializan concepciones pedagógicas, saberes y prácticas - como ejemplares de una cultura escolar. La primera parte abarca la cultura material escolar como un conjunto de documentos/fuentes que contribuyen para desnudar la "caja negra" de la escuela, y la necesidad de salvaguardarla como ejemplar del patrimonio histórico y educativo; la segunda parte se ocupa de los manuales didácticos como objetos-huella que, entrelazados con otras fuentes, pueden proporcionar pistas sobre el funcionamiento interno de la escuela. Por último, se presentan dos manuales didácticos y las alternativas de investigación histórica que vienen de ellos.

Palabras clave: Historia de la educación. Manuales didácticos. Patrimonio histórico-educativo. Cultura material escolar.

\section{INTRODUÇÃO}

$\mathrm{Na}$ esteira das novas correntes historiográficas, elegeram-se na escola novos e múltiplos objetos de investigação, como o currículo, a arquitetura, as práticas, a trajetória de professores, o perfil de alunos, as disciplinas, os rituais e representações, a cultura material escolar, entre outros. Ao analisarem o campo da historiografia da educação e suas fontes, Nunes e Carvalho (2005) afirmam que abordar a emergência de novos objetos na produção historiográfica contemporânea já se tornou trivial. No entanto, as autoras concebem que os pesquisadores pouco se atentam para a questão de que " $[\ldots]$ os novos objetos da chamada nova história são novos na medida em que 
são objetos cuja historicidade adquire visibilidade, fazendo com que estudos sobre sua história passem a ser pensados como possíveis e relevantes. (NUNES; CARVALHO, 2005, p. 45).

Entre esses objetos de estudo cuja historicidade foi, paulatinamente, sendo colocada em evidência pelos historiadores da educação, encontram-se os escolares, designados como materiais, utensílios ou artefatos. Quase a totalidade das pesquisas que se dedicam à investigação de tais objetos está relacionada à pesquisa acerca das culturas escolares, aproximando-se do que se convencionou chamar de cultura material escolar. Conforme Souza (2007, p. 180): “A história da cultura material escolar compreende, portanto, um amplo programa de pesquisa e demanda refinamento conceitual, teórico, analítico e a exploração de um conjunto significativo de fontes de pesquisa, incluindo necessariamente fontes materiais (os próprios artefatos)."

A autora ressalta que as pesquisas nesse campo ainda estão em expansão, enfatizando a ampliação do conhecimento sobre os artefatos da cultura material escolar, considerando a materialidade não simplesmente como fonte, mas como objeto de análise (SOUZA, 2007). Pesquisadores da educação têm buscado ferramentas teórico-metodológicas para construir análises sobre os artefatos e a partir deles, pois entendem que tais materiais podem constituir objeto e fonte de pesquisa.

De acordo com Souza (2007), das pesquisas acerca da materialidade da escola, as mais significativas (porque abrangem um leque numeroso) são as que tomam os livros (entre eles, os didáticos) e os cadernos escolares. Enquanto os estudos referentes ao mobiliário, utensílios de escrita, materiais visuais, sonoros e táteis, instrumentos organizadores do ensino, bem como jogos, brinquedos, ornamentos e trabalhos de alunos, entre outras expressões materiais, reúnem ainda um número reduzido de análise. Há que se considerar a conjuntura da publicação de Souza (2007), quando havia poucos estudos dedicados à história da cultura material escolar no Brasil. Nesse contexto, esse subcampo de pesquisa ainda se encontrava em construção; atualmente, esforços têm sido envidados no sentido de definir melhor a cultura material escolar enquanto fonte e objeto de análise histórica.

Ainda que nos últimos anos o número de trabalhos de pesquisa nessa área tenha aumentado, pode-se afirmar que a expressão cultura material escolar é bastante recente no campo da educação. Antes da sua emergência era comum falar-se em "materiais escolares" para intitular o conjunto de artefatos necessários para o funcionamento da escola, desde a mobília, passando pela arquitetura do prédio, laboratórios, mapas, cartilhas, livros de leitura e manuais didáticos. Souza (2007) afiança que a expressão cultura material escolar emergiu na História da Educação, fortemente 
inspirada pelos estudos em cultura escolar, pela renovação na área provocada pela História Cultural e, também, pela preocupação crescente dos historiadores em relação à preservação de fontes de pesquisa e de memória educacional em arquivos escolares, museus e centros de documentação.

Tão crescente quanto o "encantamento" pela pesquisa historiográfica sobre tais artefatos escolares tem sido a sedução pela salvaguarda desse patrimônio histórico-educativo. $\mathrm{O}$ fato é que o esforço em lembrar, em manter o passado presente, está em evidência. Nessa direção, os arquivos escolares emergem como temática recorrente no campo da História da Educação. Os acervos institucionais e pessoais que contêm documentação escolar como atas, livros de registros, termos de exame e aproveitamento escolar, relatórios de inspetores, manuais didáticos, documentos produzidos por alunos e professores e fotografias possuem potencial historiográfico e vêm mobilizando pesquisadores da área, renovando, assim, as práticas da pesquisa e motivando uma nova abordagem metodológica. Essa procura acabou demandando um esforço maior de sistematização e disponibilização dessas informações, estimulando a constituição de grupos de pesquisa voltados para a ampliação do mapeamento dessas fontes documentais.

Faz-se importante destacar a necessidade de salvaguardar, também, os manuais didáticos, artefatos escolares, constituintes e constituidores de culturas escolares e exemplares do patrimônio histórico-educativo. Diante do avanço contínuo da História Cultural em todas as áreas, inclusive na História da Educação, os manuais didáticos passaram a ser vistos pelos pesquisadores desse subcampo sob outras perspectivas, especialmente pelas suas características materiais. Enquanto o conceito de cultura escolar ${ }^{2}$ era elaborado, tornava-se evidente que esses manuais, em todas as suas formas, constituíam partes não somente integrantes dessa cultura, mas também elementos fundamentais para sua distinção. A junção fatal dessas pesquisas com o desenvolvimento simultâneo da história das disciplinas escolares e dos currículos tornou possível o realce da importância do manual didático como objeto de investigação histórica da escolarização em geral.

Ainda que, para Souza (2007), a análise dos livros como artefatos não seja nenhuma novidade no subcampo da História da Educação, considera-se instigante o estudo dos manuais didáticos para além das suas prescrições. Porque na busca da compreensão do funcionamento interno da escola, das práticas cotidianas que ocorrem no âmbito escolar, ou como disse Julia (2001), do desnudamento da "caixa preta" da escola, os manuais didáticos utilizados na formação e aperfeiçoamento de profes- 
sores emergem como uma das fontes mais profícuas para se adentrar o universo das práticas escolares.

Esses artefatos podem ser inquiridos como elementos de uma cultura escolar específica, produtos e produtores de conhecimentos escolares, edificadores de modos de fazer a escolarização, normatizadores de práticas pedagógicas escolares e, por fim, construtores de identidades e subjetivações. Essa perspectiva de análise pode ser incluída no campo de pesquisa histórico-educativa em ascensão, cognominado pelo historiador espanhol Escolano Benito manualística, o qual abrange os manuais como sintetizadores da cultura empírica da escola, suportes educativos, pedagógicos, históricos e como instrumentos de informação e seleção do conhecimento considerado científico, portanto, como fonte de conhecimento para o estudo da cultura escolar. Porque se considera que os manuais didáticos representam objetos indiciários ou objetos-huella, que podem "revelar" elementos acerca do jogo escolar. Para explicar a expressão objetos-huella, Escolano Benito (2010, p. 6) toma emprestada a qualificação “indiciários” de Ginzburg (1990, grifo do autor), afirmando que:

La historia material se construye principalmente a partir de los objetos. Estos útiles que nutren las colecciones etnográficas, o sus representaciones, nos acercan lo lejano, lo ausente, como dice Carlo Ginzburg, y una vez sustraídos de sus ámbitos de uso y ubicados en una exposición o en un catálogo, se tornan en objetos "semióforos", esto es, se convierten en materiales que portan significados que hay que descifrar por los indicios que sugieren al observador.

Inquirir os manuais didáticos - na condição de documentos materiais privilegiados para a compreensão das prescrições curriculares para determinado público e contexto - e entrecruzá-los com outras fontes pode contribuir para "despir" a cultura escolar de determinado espaço/tempo, mostrando, além das mensagens emitidas pelos textos curriculares, as apropriações de seus receptores. O desafio que se propõe é dilatar os limites metodológicos de forma a ampliar o objeto de estudo e perscrutar, além dos manuais, outras fontes, como, por exemplo, regulamentos, programas, cadernos, comunicados, atas de reunião, relatórios, planos de aula, entre outros, os quais podem nos permitir ir além das emissões/prescrições.

$\mathrm{Na}$ mesma direção dos estudos que propõem problematizar a cultura material da escola a partir dos artefatos que constituíram essa instituição, no artigo em tela se propõem possibilidades de pesquisa acerca de manuais didáticos. Tais manuais são considerados documentos, objetos culturais produzidos por um agente específico, a partir de técnicas demarcadas em uma conjuntura econômica, comercial e de orga- 
nização da produção que condiciona seu caráter social e histórico. Portanto, sugere-se tomar os manuais enquanto bens culturais que incorporam intenções, objetivos e regulações como fontes que informam sobre os valores partilhados em determinado contexto, as representações sociais e as práticas escolares (ROCHA; SOMOZA, 2012) e que, nesse sentido, contribuem para descortinar a "caixa preta" da escola. Recomenda-se inquirir os manuais (objetos) e transformá-los em documentos (fontes) a partir da prática historiográfica, historicizando-os, tal qual nos ensina Certeau (2000, p. 81, grifo do autor):

Em história, tudo começa com o gesto de separar, de reunir, de transformar em "documentos" certos objetos distribuídos de outra maneira. Esta nova distribuição cultural é o primeiro trabalho. Na realidade, ela consiste em produzir tais documentos, pelo simples fato de recopiar, transcrever ou fotografar estes objetos mudando ao mesmo tempo o seu lugar e o seu estatuto. Este gesto consiste em "isolar" um corpo, como se faz em física, e em "desfigurar" as coisas para constituí-las como peças que preencham lacunas de um conjunto, proposto a priori.

Para tanto, o texto em tela foi estruturado da seguinte forma: na primeira parte aborda-se a cultura material escolar como um conjunto de documentos (fontes/ objetos) que contribuem para o esquadrinhamento da "caixa preta" da escola e a necessidade de salvaguardá-los como exemplares do patrimônio histórico-educativo; na segunda parte, trata-se dos manuais didáticos como objetos-huella que, entrecruzados com outras fontes, podem realçar indícios sobre o funcionamento interno da escola, suas práticas e apropriações; e, por fim, apresentam-se dois manuais didáticos e as alternativas de pesquisa histórica que deles advêm.

\section{CULTURA MATERIAL ESCOLAR: PATRIMÔNIO HISTÓRICO-EDUCATIVO QUE CONTRIBUI PARA O DESNUDAMENTO DA "CAIXA PRETA" DA ESCOLA}

Atualmente os artefatos emergem como fontes e objetos de análise, como vestígios do passado, e recebem o estatuto de "documento", sendo inquiridos por meio das lentes críticas do historiador. Nessa mesma onda, no campo da História da Educação, os objetos da escola são tomados como fontes e problematizados como temáticas de pesquisa, sendo indagados pelos estudos sobre a história da arquitetura escolar e a história das instituições educativas, que enfatiza os aspectos internos da escola ou o que se convencionou chamar de cultura escolar; pelos estudos da história da leitura e da escrita, em que os textos curriculares ganham ênfase, desde os pro- 
gramas de ensino, cadernos, diários, livros de leitura, manuais didáticos e todo um conjunto de suportes materiais de difusão e circulação de ideias; e, também, pelas investigações que se voltam para questões relacionadas à preservação do patrimônio histórico-educativo (SOUZA, 2007).

No terreno ainda movediço das pesquisas no subcampo da história da cultura material, importa desnaturalizar os objetos escolares recuperando sua historicidade, compreendendo-os como produtos humanos, como objetos culturais com função e uso escolar. Interessa compreender o conjunto desses artefatos como objetos enraizados na própria forma escolar de educação e, então, problematizar a respeito do papel desses artefatos no processo educacional, indagando se são eles vestígios das finalidades culturais da escola. Assim aponta Escolano Benito (1990, p. 7 apud SOUZA, 2007, p. 174):

Los textos, el mobiliário, los espacios y todos los elementos que conponen el utillaje escolar hablan también de nustros modos de pensar y de sentir, de los sistemas de valores que informaron la educación, de la intrahistoria de la escuela y de las relaciones de ésta on la sociedad de cada época.

No entendimento de Escolano Benito (2010), a escola tem legado utensílios materiais que são representações de sua cultura empírica, de uma tradição corporativa agregada ao ofício do professor e, também, aos discursos teóricos e normativos projetados sobre a escolarização. Nesse sentido, a investigação dos artefatos pode contribuir para o entendimento dos jogos travados no interior da escola. Nessa direção, a cultura escolar ${ }^{3}$ - definida por Viñao Frago (1995, p. 69) como "[...] toda la vida escolar: hechos e ideas, mentes y cuerpos, objetos y conductas, modos de pensar, decir y hacer" - deve ser tomada como categoria de análise que contribui na interpelação das fontes e no trabalho de cotejamento dos arquivos, atentando-se tanto para as continuidades e permanências quanto para as mudanças quase invisíveis que transformam o universo escolar. Para Souza (2007, p. 180), “[...] o estudo histórico dos materiais escolares pode ser um instrumento valioso para se decifrar a cultura escolar à medida que as práticas são mediatizadas, em muitos sentidos, pelas condições materiais."

Bucaille e Pesez (1989) asseveram que a noção de cultura material está mais próxima de uma ideia/expressão do que propriamente de um conceito, cuja constituição no percurso da história tem início em meados de 1850 , período em que a ciência aplica a atenção ao concreto e ao desejo de nele basear as explicações. Até os anos 1920, aproximadamente, é que a noção conclui seu "processo de maturação" e se corporifica. Nesse momento, passa a ser objeto de história, e o estudo da cultura 
material torna-se, então, história da cultura material. A explicação sobre os objetos deve introduzi-los onde poderão encontrar o seu lugar e o seu significado. Para isso, faz-se necessário explorar o objeto em termos de dimensão, forma, matéria, modos de fabricação e proveniência, para que seja possível conhecer, analisar e compreender o ambiente que o origou, assim como o grupo sociocultural de onde provém, a época, como e porque foi concebido, apropriado e utilizado.

Ulpiano Bezerra de Meneses - intelectual de referência nas discussões acerca da cultura material - afirma que o interesse da pesquisa deve recair sobre o estudo da sociedade, entretanto estudá-la integralmente não é tarefa fácil. Tentando amenizar esse problema, o pesquisador seleciona pontos de observação, "fatias" entre as quais estão a arte e os objetos. Nessa trajetória, Meneses (2011, p. 422) afirma que não deve haver uma história da cultura material, pois:

[...] aí não é história, é história documental, é história de fonte. Você estaria confundindo a fonte com o problema. Você faz a história das meias, das escovas de dente, do que quer que seja [...] Mas, para mim, a cultura material deve dar conta da dimensão material de qualquer segmento da vida social. Em todos os segmentos da história há uma dimensão sensorial: na história econômica, na história política, na história institucional, na história das minorias, das maiorias, seja lá o que for. Então, a ideia de uma história à parte do material, para mim, desfigura a natureza do problema histórico.

Nessa perspectiva os artefatos devem ser tomados como documentos para estudar a escola e a sociedade e receber o estatuto de uma das dimensões do jogo social, do contrário, será feita uma história da fonte, como aponta o autor. Deve-se buscar a história nas coisas e não das coisas, o foco não são os objetos, mas a sociedade e as relações sociais que constituirão a educação e a escola. Para Meneses (2011), o estudo da cultura material não deve ser e não é o estudo das fontes materiais. A natureza do problema histórico é que vai possibilitar a configuração da materialidade a ser trabalhada. Então, supõe-se que as fontes materiais tenham um conteúdo específico, algo a dizer, no entanto, não se trata de fazer história das fontes. Os objetos escolares devem assumir o mesmo estatuto de qualquer outro documento, sendo utilizados/inquiridos quando capazes de auxiliar a compreender o problema da pesquisa, ao invés de ser tomados como o problema. Nenhum documento fala por si só, e o documento material segue a mesma regra (MENESES, 1998).

Escolano Benito (2010) também reflete sobre a valorização da cultura material escolar por parte da historiografia da educação, no sentido de que os artefatos 
escolares podem ser vistos como fontes essenciais para o conhecimento do passado da escola nas suas dimensões práticas e discursivas. E assevera que:

La nueva historia cultural, através de sus líneas etnográfica $y$ microhistórica, principalmente, viene tratando de configurar un nuevo campo historiográfico en torno al estudio de las materialidades de la escuela, no como un ámbito polarizado simplistamente hacia la historia instrumental, sino como una orientación investigadora que puede ser incluso globalizante en la medida en que desde lo material, examinado siempre en sus significaciones culturales, se puede estructurar toda una historia holística de la educación que estudie los usos de los objetos, las vinculaciones de unos materiales con otros, las relaciones de estos con los actores y con las prácticas empíricas que ponen en acción, su ubicación en los espacios institucionales y la imbricación de todas estas mediaciones en la estructuración de la tecnología de la enseñanza como modo de producción. (ESCOLANO BENITO, 2010, p. 17).

Para o autor, a escola é um lugar de produção de cultura, a qual se objetiva nas práticas em que se operacionalizam os processos formativos. As ações se materializam espaços, objetos e textos que formam parte do patrimônio histórico-educativo de um contexto. Para Souza (2013, p. 212), as justificativas para a preservação do patrimônio histórico-educativo ressaltam a importância da conservação da memória da escola, “[...] remetendo a seus vínculos com a formação da infância e da juventude e a espaço de transmissão de cultura e processos de construção de subjetividades e de identidades"; além da importância da salvaguarda das fontes de pesquisa para as investigações em História da Educação.

Meneses (2005) aponta as "funções" de um acervo escolar destinado a salvaguardar o patrimônio histórico-educativo, entre elas citam-se: recuperar a memória da História da Educação regional, preservando todo o tipo de material e constituindo acervos documentais temáticos; disponibilizar um acervo documental com fontes impressas, manuscritas e iconográficas; constituir um acervo de dissertações e teses produzidas no campo da História da Educação; reconstituir a materialidade das rotinas e do cotidiano escolar: carteiras escolares, mesas, lousas, lápis, canetas, palmatórias, cadernos escolares, manuais didáticos, etc.; recolher e catalogar materiais doados por instituições ou pessoas e, por fim, promover exposições e mostras sobre História da Educação.

Reconhecer a cultura material da escola como patrimônio histórico-educativo e salvaguardá-la como tal implica preservar, comunicar e interpelar os artefatos escolares como bens culturais, os quais, selecionados por determinada sociedade, devem ser preservados como herança patrimonial. Faz-se mister ressaltar que a musealização dos objetos faz com que estes percam a sua função primária e adquiram significado de bem 
cultural. Ao serem musealizados, os artefatos se transformam em documentos, processo que, para Meneses (2005), é o eixo da prática de musealizar, e representam as memórias de uma época, de uma cultura, de antigos processos educacionais que não podem cair no esquecimento. Nesse sentido, ao serem expostos em seus acervos, os artefatos não serão apenas observados e admirados, deverão ser inquiridos.

Entre os artefatos escolares a serem musealizados destacam-se os manuais didáticos para a formação de professores, que “[...] não são simples objetos ou meios técnicos para implementar uma proposta pedagógica; são espaços de memória que representam códigos de vida das instituições e dos homens que as conformam." (CUNHA, 2012, p. 20). Porque como afirma Chartier (1990, p. 127), “[...] não existe texto fora do suporte que o dá a ler, que não há compreensão de um escrito, qualquer que ele seja, que não dependa das formas através das quais ele chega a seu leitor."

Magalhães (2008, p. 7) concorda com o potencial do manual na condição de objeto de análise e fonte histórica afirmando que "[...] no quadro da sua materialidade, em sentido amplo, o manual escolar contém uma informação científica e uma configuração autoral e editorial que lhe conferem autenticidade como representação da cultura escolar." Sendo o manual o principal suporte da cultura escolar, portador de uma memória, de uma informação, de uma projeção, “[...] há no complexo teórico e na configuração do manual uma modelação do aluno e uma idealização da sociedade." (MAGALHÃES, 2008. p. 7).

Para Cunha (2012), conhecer as condições de produção dos livros e como estes são dados a ler e são utilizados pode contribuir para a compreensão de como o Estado fez da leitura um saber escolar e determinou à escola a responsabilidade de formar leitores. Reconhecendo a importância da preservação dos livros escolares, entre os quais se destacam os manuais didáticos, é imprescindível que se programem políticas com a finalidade de enriquecer a relação da sociedade com seus bens culturais. E, para tanto, emerge a necessidade da constituição e da manutenção de acervos escolares.

\section{MANUAIS DIDÁTICOS COMO OBJETOS-HUELLA}

De acordo com Bufrem et al. (2006), sendo destinados ao uso e à formação de professores, os manuais didáticos podem ser tomados como fontes para se indagar sobre a presença de elementos que, em certos períodos históricos, definiram as formas de se pensar e de se desenvolver o ensino. Portanto, é possível inquiri-los como elementos da cultura escolar, produtos e produtores de conhecimentos escolares, edi- 
ficadores de modos de fazer a escolarização, normatizadores de práticas pedagógicas escolares e, por fim, construtores de identidades e subjetivações.

Mesmo na contemporaneidade, com a infinidade de outras tecnologias educacionais, os manuais didáticos permanecem presentes em sala de aula, revelando sua irrefutável relevância para o estudo da cultura escolar, incitando a criação de centros de estudo ${ }^{4}$ e originando um novo campo de pesquisa histórico-educativa, a manualística. Esse campo abrange os manuais escolares como sintetizadores da cultura empírica da escola, como suportes educativos, pedagógicos e históricos e como instrumentos de informação e seleção do conhecimento considerado científico, portanto, fonte de conhecimento para o estudo da cultura escolar. E, assim, os manuais representam objetos indiciários ou objetos-huella, que podem revelar elementos acerca dos jogos escolares (ESCOLANO BENITO, 2012).

Se nos seus primórdios a investigação sobre manuais escolares esteve centrada nos conteúdos das disciplinas humanísticas, observando nestes um caráter ideológico de formação das identidades nacionais, com o passar dos anos e a renovação de metodologias e perspectivas teóricas, as pesquisas começaram a abarcar todos os campos das disciplinas escolares. Elas passaram a analisar para além da sua influência na formação das consciências individuais ou coletivas e agir de forma a realizar uma genealogia dessas disciplinas, atentando para os fatores que influenciam a seleção curricular, os autores de livros escolares, a história das editoras, etc., até chegar à contemporaneidade, em que uma parcela significativa dos estudos historiográficos considera esses manuais como parte da cultura escolar. Escolano Benito (2001, p. 14) advoga em favor dessa causa:

Los estudios sobre manualistica han de elucidar precisamente los modos de producción y de apropiación de estos materiales de la cultura de la escuela, que no son sólo vehículos de las disciplinas académicas, sino representaciones que expresan, en sus mismas formalidades, y hasta en sus simulacros lingüisticos, toda una semántica y una pedagogía.

O mesmo autor afiança que os manuais escolares podem ser percebidos como um dos sintetizadores mais visíveis da cultura escolar, porque podem ser examinados como representações de "[...] las prácticas que prevé e induce, como un soporte en el que subyacen los discursos pedagógicos acerca de la acción escolar y como un objeto indiciario de los valores en que se fundamenta la administración que lo regula" (ESCOLANO BENITO, 2012, p. 43). E, em outro momento, acrescenta que os manuais, enquanto parte da cultura escolar, guardam 
[...] ciertos testimonios de la "gramática de la escolarización" de la que hablan algunos, un código invisible pero reglado que hace que la cultura escolar sea en parte un orden sistémico relativamente cohesionado y estable, expresión al tiempo del habitus profesional de los enseñantes y de los estereotipos en que se han socializado los sujetos (ESCOLANO BENITO, 2010, p. 14 , grifo do autor).

Nesse sentido, os livros escolares, entre eles os didáticos, são fontes da nova historiografia, mas são, também, construções culturais e educacionais codificadas de acordo com as especificidades de cada contexto de produção e de circulação. Além de fontes para entender a cultura escolar de determinada conjuntura, configuram-se também como objetos de análise, como configurações históricas, podendo ser analisados ao nível material e simbólico, como representação da cultura escolar, porque neles estão contidas as estratégias pensadas para a educação formal, o imaginário social e os métodos didáticos de determinada época. Como base da ação pedagógica, os manuais didáticos podem conter indícios da tal "caixa preta" que tanto se deseja esmiuçar.

Badanelli (2010, p. 47-49) corrobora essa hipótese afirmando que o conjunto de livros/manuais utilizados nas instituições educativas é uma das fontes históricas mais importantes porque "[...] son parte integrante del patrimonio histórico-educativo" e se situam no "[...] punto de inflexión de las prescripciones fijadas, abstractas y generales de los programas oficiales, $y$ del discurso singular y concreto que desarrolla cada maestro en su clase". Ademais, essa autora aponta algumas características dos manuais que os fazem fontes privilegiadas de pesquisa, como, por exemplo, o fato de se manterem ao longo do tempo com uma produção inesgotável, haja vista que novas edições substituem as produções já obsoletas; além de serem “[...] reeditados en gran cantidad, no sólo con el objetivo de renovar el ejemplar, ni por el natural desgaste de las obras, sino que, en muchas ocasiones, se reeditan con contenidos diferentes." (BADANELLI, 2010, p. 49).

Ainda que os manuais didáticos estejam sendo tomados no texto em tela como fontes singulares para adentrar a internalidade da escola, algumas precauções devem ser tomadas ao se trabalhar com tal materialidade. Um problema metodológico que pode ocorrer no interesse de perscrutar as práticas escolares é saber como tais manuais foram utilizados. A partir desse obstáculo, Badanelli (2010) propõe que se amplie o objeto de análise, entrecruzando-se os manuais com outras fontes específicas e, por que não dizer, ordinárias, daquele contexto escolar, como, por exemplo, fontes orais, cadernos escolares, exames, diários de classe, entre outras. 
Ossenbach Sauter (2010) defende os manuais como parte integrante do patrimônio histórico-educativo, não somente como suportes da memória individual e coletiva, mas também porque constituem uma fonte imprescindível para a compreensão das práticas internas do universo escolar. Para a autora, esses manuais não constituem uma descrição ou um registro fotográfico de determinada sociedade e sua cultura, mas podem configurar indícios de um

[...] horizonte idealizado de saberes, propósitos y valoraciones, un conjunto de interpretaciones y de posicionamientos que expresan visiones subjetivas del mundo social, susceptibles, a su vez, de ser analizadas para tratar de comprender la historia escolar y los procesos de transmisión cultural. (OSSENBACH SAUTER, 2010, p. 124).

No entanto, a autora também propõe algumas precauções metodológicas nas investigações que envolvem os manuais, sobretudo ressaltando que não se deve limitar o estudo às suas prescrições, ou seja: “[...] no debería limitarse a tratarlos como “emisores” de mensajes, códigos y contenidos que deben ser descifrados, sino que también es preciso conocer el uso que se ha hecho de ellos en el aula y, sobre todo, su apropiación por parte de los sujetos que aprenden ("receptores"). (OSSENBACH SAUTER, 2010, p. 126, grifo do autor).

De acordo com Teive (2014), Ossenbach Sauter provoca reflexões a respeito da manualística fomentando o debate sobre uma possível ênfase exagerada e muito centrada nas prescrições dos manuais a serem analisados. Sobretudo no Workshop Italo-Español sobre a Historia de la cultura escolar, organizado pelo Centro de Investigación en Manuales Escolares (Manes), pelo Centro Internacional de la Cultura Escolar (CEINCE) e pela Università Degli Studi de Macerata, na Itália, em novembro de 2011. Nesse evento, a atual diretora do Manes incita pensar sobre essa prática centrada nas prescrições ou no caráter de emissor dos manuais e no fato de que algumas das linhas investigativas empreendidas na manualística teriam esgotado as possibilidades de contribuir para as investigações da cultura escolar, isto é, para a compreensão dos processos de ensino e aprendizagem e, também, das tradições e regularidades estratificadas ao longo do tempo nas práticas ocorridas no interior das instituições educativas. Para Teive (2014, p. 835, grifo do autor), na avaliação de Ossenbach Sauter:

[... o foco dado pelo Centro de Investigación MANES à análise dos "emissores das mensagens" dos livros, seja no que se refere ao currículo prescrito pelas políticas e legislação, seja pelo currículo apresentado aos professores, não estaria contribuindo para o avanço das investigações no campo da história da cultura 
escolar, área que vem mobilizando muitos de seus pesquisadores a partir dos anos 2000 .

Dessa forma, o desafio que se impõe para esse campo de pesquisa é encontrar fontes outras que - entrecruzadas com os manuais - possam proporcionar aos historiadores da educação indícios da história da prática nas salas de aula, das mensagens veiculadas e das apropriações realizadas pelos agentes escolares.

\section{MANUAIS DIDÁTICOS ESCRITOS POR EVERARDO ADOLPHO BACKHEUSER: POSSIBILIDADES DE PESQUISA}

Na esteira do movimento que focaliza os manuais didáticos como objetos e fontes de análise, propõe-se como possibilidade para a pesquisa histórica tomar dois dos manuais didáticos - escolanovistas - produzidos para a formação e o aperfeiçoamento de professores primários, escritos pelo intelectual católico Everardo Adolpho Backheuser. Nesse sentido, seria necessário atentar para o contexto de produção e circulação desses escritos, perscrutá-los na sua materialidade, como objetos culturais produzidos por um agente específico, a partir de técnicas demarcadas em uma conjuntura política, econômica, comercial e de organização da produção que condiciona seu caráter social e histórico. Ao se analisarem os manuais na condição de bens culturais que incorporam intenções, objetivos e regulações, acredita-se ser possível inquiri-los como fontes que podem informar sobre os valores partilhados em determinado contexto, as representações sociais e as práticas escolares, e que, nesse sentido, contribuem para realçar a maquinaria da "caixa preta" da escola.

Pelo menos três alternativas de pesquisa saltam aos olhos ao se tomarem como objetos/fontes os manuais: Técnica da Pedagogia Moderna (Teoria e Prática da Escola Nova) de 1934 e Manual de Pedagogia Moderna (Teórica e Prática) de 1948. A primeira delas analisaria o processo de incorporação das concepções pedagógicas da Escola Nova nas prescrições para a prática pedagógica presentes nos manuais. A segunda investigaria o seu autor, a trajetória social desse intelectual no campo educacional atentando para a sua rede de sociabilidade. A terceira alternativa investigaria a circulação desses manuais didáticos nas instituições escolares, como em um jogo de escalas, considerando a legislação nacional e a estadual, bem como a recepção dessas prescrições nas escolas. 


\subsection{DESCRIÇÃO DOS MANUAIS: DETECTANDO INDÍCIOS DA ESCOLA NOVA}

A ideia de um curso sistemático de pedagogia nova foi concretizada em 1933, quando Everardo Backheuser, a pedido de Alceu Amoroso Lima, ministrou um curso sobre Escola Nova, no Instituto Católico de Estudos Superiores, no Rio de Janeiro. No ano seguinte, esse curso foi transformado em livro, eternizando-se, desse modo, por meio do texto impresso.

Assim, o seu primeiro manual didático, Técnica da Pedagogia Moderna (Teoria e Prática da Escola Nova), data de 1934, dois anos após a publicação do Manifesto dos Pioneiros da Educação Nova e três anos após a saída de Everardo Backheuser da Associação Brasileira de Educação. A partir da publicação desse manual, o autor ficou conhecido como um intelectual propositor de um escolanovismo católico. O manual é apontado como a principal referência que norteou as publicações da Revista Brasileira de Pedagogia, responsável por irradiar as ideias e discussões desenvolvidas no âmbito da Confederação Católica Brasileira de Educação, órgão que reunia educadores católicos empenhados em traduzir preceitos escolanovistas à luz do catolicismo (ERRERIAS, 2000).

A primeira edição, datada de 1934, foi publicada pela Civilização Brasileira S.A. De acordo com Narcizo (2008), esse manual fez parte da Biblioteca Brasileira de Cultura, dirigida por Alceu Amoroso Lima. Logo na primeira página o autor escreve uma dedicatória à sua esposa Alcina Backheuser, professora primária que dividiu lugar com ele nas "trincheiras" do campo educacional. Em seguida, apresenta o prefácio escrito pelo Padre Leonel Franca (militante católico de renome) e o preâmbulo, de sua autoria.

Esse manual apresenta uma subdivisão. A primeira parte que se estende até a página 311 sob o título supracitado apresenta 10 capítulos assim intitulados: I Considerações gerais; II - Princípios Cardeais da Escola Nova; III - A escola única; IV - A Pedagogia e as ciências correlatas; V - Educação integral; VI - A iniciativa; VII - A cooperação; VIII - Educar para a vida e pela vida; IX - O papel do mestre na Escola Nova; X - Detalhes da técnica da Escola Nova. O índice aparece no fim.

Na parte final da obra, inicia-se novamente a contagem das páginas, de 1 a 156, sob o título de Aritmética na Escola Nova (a nova didática da aritmética). Datada de 1933, essa publicação traz como editora a Livraria Católica e apresenta índice e preâmbulo do autor. Os capítulos são subdivididos da seguinte forma: A didática da aritmética à luz da Psicologia; Variação da Psicologia infantil com a idade; Fim do 
período escolar primário; O ensino de Aritmética no Brasil; Os fatores primordiais da didática da Aritmética; Conclusões (algumas sugestões práticas/cálculo mental).

Pode-se observar que na primeira edição do livro o autor se volta para a compreensão dos princípios cardeais da escola nova com a intenção de esclarecer e demonstrar a aplicabilidade das orientações escolanovistas para os professores. Backheuser traz tanto o plano teórico acerca do pensamento educacional escolanovista quanto o plano prático no que diz respeito às orientações didáticas ao professor. Nota-se, nessa primeira edição, a preocupação do autor em, além de esclarecer os princípios da escola nova ao seu público-alvo - o professorado -, possibilitar a sistematização desses preceitos, ressaltando a metodologia que deve ser empregada.

O segundo livro, Manual de Pedagogia Moderna (Teórica e Prática), foi publicado inicialmente em 1942, e sua quarta edição data de 1948. Nele, Backheuser faz, tal qual na primeira edição, uma dedicatória à sua esposa Alcina Backheuser, apresenta o índice, e também um prefácio da terceira edição no qual explica, resumidamente, as alterações realizadas:

Prefácio da $3^{\mathrm{a}}$ edição:

Êste livro que, em suas duas primeiras edições, apareceu sob o título de Técnica da Pedagogia Moderna sofre agora modificações profundas, não só na atualização dos informes como na própria coordenação dos antigos capítulos com a adição de outros novos que não constavam daquelas edições. Procedemos a essa verdadeira metamorfose com o objetivo, desejado pelos editôres, de torná-lo um compêndio de pedagogia para uso de escolas normais e institutos de educação. Essas circunstâncias forçaram a mudança do título da obra. (BACKHEUSER, 1948, p. 13).

O prefácio é novamente escrito pelo Padre Leonel Franca, seguido de um preâmbulo da primeira edição escrito pelo próprio autor. Em 409 páginas são distribuídos seis capítulos, subdivididos em várias seções: I - Conceito de Educação e de Pedagogia; II - Ciências basilares da Pedagogia; III - Fatores da Educação; IV - Os educadores e a Educação; V - Princípios cardeais da Escola Nova; VI - Problemas de Pedagogia prática.

À primeira vista, nessa edição, o fio condutor deixa de ser a explicação sobre os fundamentos da Escola Nova, destacando-se questões gerais da educação e da didática, além das recomendações da ação docente ainda com base no escolanovismo católico. Mesmo que haja temas e títulos repetidos da primeira edição, estes aparecem reformulados, e, em alguns momentos, Backheuser mostra a diferença entre essa edição e a primeira, acrescentando, também, comentários sobre as conquistas referentes à implantação dos princípios escolanovistas em algumas instituições. Além das perma- 
nências e mudanças de uma edição para a outra, propõe-se perceber se a apropriação do autor em relação aos preceitos escolanovistas permaneceu sob a mesma ótica do seu primeiro escrito didático.

A questão principal que norteia o estudo das prescrições seria: como os preceitos escolanovistas são representados nos manuais? Para alcançar a resposta para tal pergunta, propõe-se o entrecruzamento dos manuais com fontes seminais a respeito do movimento escolanovista, entre as quais se citam: o livro Introdução ao estudo da Escola Nova, escrito por Lourenço Filho, e o Manifesto dos Pioneiros da Educação Nova (1932). Considerando a clave filosófica do autor aqui proposto, o foco seria perceber como foi a apropriação da Escola Nova a partir de lentes católicas.

\subsection{O AUTOR EVERARDO ADOLPHO BACKHEUSER}

Partindo do princípio de que para analisar os manuais didáticos é preciso contextualizar seus autores, suas redes de sociabilidade e sua trajetória no campo educacional, apresenta-se uma breve síntese a respeito de Everardo Adolpho Backheuser.

Nasceu em 1879 em Niterói, no Rio de Janeiro, e morreu em 1951. Foi Engenheiro, Geógrafo e professor da Escola Normal de Niterói, do Colégio Pedro II, entre outras instituições. Além do exercício do magistério, dedicou-se, também, às atividades político-administrativas e jornalísticas. Em 1928, como em uma homenagem póstuma, realizou o desejo de sua primeira esposa, reconvertendo-se ao catolicismo no dia da sua missa de corpo presente (ele era de família católica, mas na adolescência havia abandonado a prática religiosa). Depois disso começou a atuar no movimento de agremiação de professores católicos e da Campanha em prol do ensino religioso.

Logo que Backheuser se aposentou como professor, interessado na reforma que Fernando de Azevedo iniciara no Rio de Janeiro (1927), passou a colaborar com ele. Foi para a Alemanha, conheceu melhor a Escola Nova, e, logo que voltou, assumiu a direção de cinco escolas municipais para ensaiar métodos e realizar análises. Nessa época iniciou a Cruzada Pedagógica em prol da Escola Nova e a publicação do boletim A Escola Nova. Promoveu atividades como excursões programadas, cinemateca, bibliotecas escolares, uso do tabuleiro de areia. Em 1929, promoveu uma Exposição Pedagógica com trabalhos de alunos. Foi membro cofundador da Associação Brasileira de Educação (1924) com a qual rompeu em 1931; em 1933 tornou-se membro fundador da Confederação Católica Brasileira de Educação. Teve textos publicados em vários periódicos, como Revista Escola Nova, Revista Brasileira de Pedagogia e Boletim dos Professores Católicos. 
Sobre o autor, interessa conhecer a sua origem sociofamiliar e os seus percursos escolar e profissional, na tentativa de compreender as seguintes questões: quais as principais facetas da trajetória desse intelectual? Como se situou no campo educacional? Como esse engenheiro, educador, militante intelectual e católico apropriou-se dos postulados do movimento da Escola Nova nos manuais didáticos que escreveu?

\subsection{RECEPÇÃO E APROPRIAÇÃO DOS MANUAIS}

Faz-se importante ressaltar que o estudo acerca dos manuais pode ir além das suas prescrições, na tentativa de perceber como ocorreu a apropriação deles nas escolas, ou seja, detectar indícios de como o manual foi recebido/apropriado pelos professores nas instituições escolares. Isso poderia ser feito por meio do entrecruzamento de fontes. Indícios da circulação desses manuais didáticos nas instituições escolares, bem como as apropriações do movimento escolanovista em suas prescrições poderiam ser detectados a partir da análise da legislação nacional e estadual, dos relatórios e planos de aula dos professores, dos regulamentos e outros documentos que circulam na escola.

Pensando numa escala nacional, deve-se lembrar que entre os anos 1942 e 1946 entrou em vigor um conjunto de Leis Federais para a educação escolar conhecido como Reforma Capanema, a qual reorganizou a estrutura educacional brasileira com o intuito de estabelecer uma política nacional de educação unificada para o País. Até 1946, o ensino primário era de responsabilidade dos governos de cada Estado. Fez parte desse conjunto a Lei Orgânica Federal do Ensino Primário - Lei n. 8.529/46 (BRASIL, 1946).

Em escala estadual, percebe-se que o Estado de Santa Catarina acompanhou o movimento nacional de renovação da educação escolar quando promulgou o Decreto Estadual n. 298, de 18 de novembro de 1946 (SANTA CATARINA, 1946), dando corpo à Lei Orgânica do Ensino Primário do Estado de Santa Catarina e demonstrando " [...] o grande desejo do Estado em sintonizar-se com as instituições federais." (FIORI, 1975, p. 153). No ensino público catarinense, a tentativa de renovação pedagógica ficou conhecida como Reforma Elpídio Barbosa, que se fundamentou em um aparato de cunho centralista e autoritário e por força de lei implementou a Escola Nova nos grupos escolares catarinenses e também nas escolas reunidas e isoladas (FIORI, 1975).

Sabendo da presença da Escola Nova na legislação educacional brasileira e catarinense, poderia-se questionar: os manuais didáticos escritos por Everardo Ba- 
ckheuser circularam nos grupos escolares, escolas reunidas e isoladas catarinenses? Os relatos documentais dos professores revelam indícios da apropriação desses manuais?

\section{CONSIDERAÇÕES FINAIS}

No texto em tela teve-se como objetivo principal fomentar reflexões em relação à potencialidade do estudo histórico da cultura material da escola, tomando, de forma especial, os manuais didáticos como objetos indiciários que materializam concepções pedagógicas e intelectuais, símbolos, códigos, saberes e práticas educacionais e, por isso, podem ser considerados exemplares de determinada cultura escolar.

Na seção 2 abordou-se a cultura material escolar como um conjunto de documentos (fontes/objetos) que pode contribuir para o descortinamento da "caixa preta" da escola e a necessidade de salvaguardá-lo na condição de exemplar do patrimônio histórico-educativo. Enfatizou-se a necessidade de desnaturalizar os artefatos da escola, historicizando-os como objetos culturais, como vestígios de um passado escolar ou representações da cultura empírica da escola. Assim, direcionar as lentes investigativas para esses artefatos pode contribuir para a compreensão das práticas travadas no interior da escola. Nesse sentido, refletiu-se sobre a noção de cultura material e como esta passa a ser objeto de pesquisas que buscam a história da sociedade e da escola a partir dos objetos que compõem essa cultura material, os quais, por meio do olhar crítico do historiador, recebem o estatuto de fontes documentais. Justamente porque podem revelar indícios de práticas ocorridas no interior da escola, esses artefatos devem ser guardados como patrimônio histórico-educativo. Vimos, no texto, que muitas iniciativas estão sendo tomadas nessa direção para conservar a memória da escola.

Entre os artefatos escolares a serem salvaguardados destacaram-se os manuais didáticos como suportes da cultura escolar e como espaços de memória. Nesse sentido, na seção 3 propôs-se pensar nos manuais didáticos como objetos-huella que, entrecruzados com outras fontes, podem desvelar indícios sobre as formas de pensar e desenvolver o ensino, o funcionamento interno da escola, suas práticas e apropriações. Dentro dessa reflexão, citou-se o campo de investigação denominado manualística, o qual abrange os manuais escolares, entre os quais, os didáticos. Além disso, frisou-se a necessidade de algumas precauções metodológicas no estudo desses artefatos. Uma delas diz respeito ao perigo de se limitar apenas aos estudos das mensagens dos emissores, ou seja, das prescrições contidas nesses manuais. Propõe-se, então, ampliar o âmbito da análise tomando outras fontes que, entrecruzadas com es- 
ses manuais didáticos, possam revelar indícios da história da prática nas salas de aula, desde as mensagens vinculadas até a recepção e apropriação dos agentes escolares.

Por fim, na seção 4, optou-se por elencar três alternativas de pesquisa tomando como fontes e objetos de análise os dois manuais selecionados. Na subseção 4.1, foram tecnicamente descritos os dois manuais comparando-se Técnica da Pedagogia Moderna (Teoria e Prática da Escola Nova), de 1934, e Manual de Pedagogia Moderna (Teoria e Prática), de 1948. Uma análise preliminar detectou indícios do movimento escolanovista nas suas prescrições e demonstrou que essas são duas versões do mesmo manual, modificado a pedido dos seus editores. Nesse sentido, propôs-se o entrecruzamento de fontes, entre bibliografias que tragam os princípios cardeais do movimento escolanovista e aqueles presentes nos manuais, atentando-se para a forma com que foram ressignificados/reapresentados pelo autor católico. Na subseção 4.2 tentou-se mostrar a importância de se conhecer o autor do manual selecionado, identificando a sua rede de sociabilidade e compreendendo sua trajetória social (origem sociofamiliar e percursos escolar e profissional) e sua atuação no campo educacional. Para a pesquisa que se apresentou, tratou-se de Everardo Adolpho Backheuser, engenheiro, professor e militante católico e escolanovista, o qual teve significativa atuação na conjuntura brasileira das décadas de 1920 e 1930. Na última subseção, 4.3, pretendeu-se mostrar que o estudo pode ir além das mensagens prescritas nos manuais, adentrando-se ao terreno de recepção e apropriação delas no interior da escola. Para tanto, seria preciso detectar indícios da Escola Nova nos documentos relacionados à legislação educacional daquele contexto, além de relatórios, planos de aula, programas, etc.

Acredita-se que pesquisas do tipo que se propôs aqui podem contribuir para o campo investigativo da História da Educação. Campo que nas últimas décadas volta suas lentes para o funcionamento interno da escola por meio da tentativa de compreensão das práticas cotidianas que ocorrem no âmbito escolar, tomando os livros utilizados na formação de professores uma das fontes mais profícuas para adentrar esse universo. Almeja-se atentar para o contexto de produção e circulação desses manuais didáticos, perscrutá-los na sua materialidade, como objetos culturais produzidos por um agente específico, analisar esses manuais enquanto bens culturais que incorporam intenções, objetivos e regulações, e, por fim, inquiri-los como fontes que podem informar sobre os valores partilhados em determinado contexto, as representações sociais e as práticas escolares, que, nesse sentido, contribuem para a compreensão dos jogos que compõem a "caixa preta" da escola. 
Notas explicativas

${ }^{1}$ Este artigo é fruto de uma tese de doutoramento que está sendo desenvolvida pela autora do artigo e orientada pela coautora.

${ }^{2}$ Há aproximadamente 10 anos, a categoria cultura escolar adentrou a área da educação e o campo de pesquisa historiográfica e, desde então, tem impulsionado estudos de historiadores da educação preocupados com o funcionamento interno da escola e com o cotidiano das práticas escolares em perspectiva histórica. Os métodos de investigação vêm sendo renovados, o que provoca alterações nas práticas de pesquisa na área, recorre-se, por exemplo, à investigação etnográfica, às microanálises e aos estudos de caso, almejando-se aproximar dos fazeres ordinários da escola e, em especial, à valorização dos vários agentes escolares e suas ações cotidianas. A categoria cultura escolar possibilita o refinamento metodológico e analítico das problemáticas de investigação e, por meio dela, acrescenta-se ao estudo das normas e prescrições a atenção às práticas. A noção de cultura escolar tem fortalecido a interlocução com a história e demais áreas da educação.

${ }^{3}$ No Brasil, historiadores da educação se inspiram nos estudiosos estrangeiros apropriando-se das suas acepções de cultura escolar. A conceitualização de Julia (2001) é bastante citada, em especial em razão do destaque que dá às práticas, então, estudiosos das disciplinas e saberes escolares e da história do currículo o acolhem. A de Viñao Frago (1995) também vem sendo amplamente utilizada por investigadores brasileiros, sobretudo nos estudos acerca de espaços e tempos escolares; esse autor é citado em análises sobre o currículo, os saberes e a materialidade escolar e métodos de ensino. Chervel (1990) e Forquin (1993) são especialmente mobilizados nos estudos curriculares.

${ }^{4}$ Como exemplo, cita-se o Proyecto MANES. Fundado em Madri, na Espanha, no início da década de 1990, por iniciativa do professor Federico Gómez Rodriguez de Castro, do Departamento de Historia de la Educación y Educación Comparada, da Universidad Nacional de Educación a Distancia - UNED. Desde o seu início, o Proyecto MANES contou com a participação dos professores Agustín Escolano Benito, Antonio Viñao Frago, José Maria Hernandez Diaz, Maria Nieves Gómez, Mercedes Vico e Julio Ruiz Berrio.

\section{REFERÊNCIAS}

BACKheUSer, E. A. Manual de Pedagogia Moderna (Teórica e Prática). 5. ed. Rio de Janeiro: Porto Alegre, São Paulo: Globo, 1948.

\section{BACKheuser, E. A. Técnica da Pedagogia Moderna (Teoria e Prática da}

Escola Nova). 1. ed. Rio de Janeiro: Civilização Brasileira, 1934.

BADANELLI, A. M. La investigación histórica com manuales escolares: ventajes y limitaciones. Revista Linhas, Florianópolis, v. 11, n. 2, p. 46-67, jul./dez. 2010. Disponível em: <http://www.periodicos.udesc.br/index.php/linhas/article/ view/2130/1630>. Acesso em: 10 ago. 2014.

BRASIL. Decreto-Lei n. 8.529, de 02 de janeiro de 1946. Lei orgânica do ensino primário. Diário Oficial da União, Rio de Janeiro, 04 jan. 1946. Disponível em: $<$ http://www2.camara.leg.br/legin/fed/declei/1940-1949/decreto-lei-8529-2-janeiro-1946-458442-publicacaooriginal-1-pe.html>. Acesso em: 15 maio 2015. 
BUCAILLE, R.; PESEZ, J. M. Cultura material. In: RUGGIERO, R. (Org.). Enciclopédia Einaudi: homodomesticação e cultura material. Portugal: Imprensa Nacional, Casa da Moeda, 1989.

BUFREM, L. S.; SCHMIDT, M. A.; GARCIA, T. M. F. B. Os manuais destinados a professores como fontes para a história das formas de ensinar. Revista HISTEDBR On-line, Campinas, n. 22, p. 120-130, jun. 2006. Disponível em: <http://www.histedbr.fe.unicamp.br/revista/edicoes/22/art09_22.pdf>. Acesso em: 10 set. 2014.

CERTEAU, M. A escrita da história. Rio de Janeiro: Forense Universitária, 2000.

CHARTIER, R. A história cultural: entre práticas e representações. Tradução Maria Manuela Galhardo. Lisboa: Difel, 1990.

CHERVEL, A. História das disciplinas escolares: reflexões sobre um campo de pesquisa. Teoria \& Educação, v. 2, p. 177-229, 1990. Disponível em: <http://moodle. fct.unl.pt/pluginfile.php/122510/mod_resource/content/0/Leituras/Chervel01.pdf $>$. Acesso em: 07 dez. 2015.

CUNHA, M. T. S. Rastros de leituras: um estudo no acervo de livros do Museu da Escola Catarinense (décadas de 20 a 60 do século XX). Educação, Porto Alegre, v. 35, n. 1, p. 18-27, jan./abr. 2012. Disponível em: <http://revistaseletronicas.pucrs.br/ ojs/index.php/faced/article/download/10347/7537>. Acesso em: 01 set. 2014.

ENTREVISTA com Ulpiano Toledo Bezerra de Meneses. Estudos Históricos, Rio de Janeiro, v. 24, n. 48, p. 405-431, jul./dez. 2011. Disponível em: <http://www. scielo.br/pdf/eh/v24n48/09.pdf>. Acesso em: 17 ago. 2014.

ERRERIAS, C. A. C. Catolicismo e educação na década de 1930: o escolanovismo de Everardo Backheuser. 2000. Dissertação (Mestrado em Educação Escolar)Faculdade de Ciências e Letras, Universidade Estadual Paulista, Araraquara, 2000.

ESCOLANO BENITO, A. El manual como texto. Pro-Posições, v. 23, n. 3 (69), p. 33-50, set./dez. 2012. Disponível em: <http://www.scielo.br/pdf/pp/v23n3/03.pdf>. Acesso em: 01 ago. 2014.

ESCOLANO BENITO, A. Patrimonio material de la escuela e historia cultural. Revista Linhas, Florianópolis, v. 11, n. 2, p. 13-28, jul./dez. 2010. Disponível em: $<$ http://www. periodicos.udesc.br/index.php/linhas/article/view/212>. Acesso em: 05 ago. 2014.

ESCOLANO BENITO, A. Sobre la construcción histórica de la manualística en España. Revista Educación y Pedagogía, Medellín: Facultad de Educación, v. 13, n. 29-30, p. 13-24, enero/sept. 2001. Disponível em: <http://aprendeenlinea.udea.edu.co/ revistas/index.php/revistaeyp/article/viewFile/7503/6906>. Acesso em: 05 set. 2014. 
FIORI, N. Aspectos da evolução do ensino público: ensino público e política de assimilação no estado de Santa Catarina nos períodos imperial e republicano. 2 ed. Florianópolis: Ed. UFSC, 1991.

FORQUIN, J. C. Escola e cultura: as bases sociais e epistemológicas do conhecimento escolar. Tradução Guacira Lopes Louro. Porto Alegre: Artes Médicas, 1993.

GINZBURG, C. Sinais: raízes de um paradigma indiciário. In: GINZBURG, C. (Org.). Mitos, emblemas, sinais: morfologia e história. São Paulo: Companhia das Letras, 1990.

JULIA, D. A cultura escolar como objeto histórico. Revista Brasileira de História da Educação, Campinas, n. 1, p. 9-44, 2001. Disponível em: <http://www.rbhe. sbhe.org.br/index.php/rbhe/article/download/273/281>. Acesso em: 01 abr. 2014.

LOURENÇO FILHO, M. B. Introdução ao estudo da escola nova: bases, sistemas e diretrizes da Pedagogia contemporânea. 14. ed. São Paulo: Melhoramentos, 2002.

MAGALHÃES, J. O manual escolar como fonte historiográfica. In: COSTA, J. V.; FELGUEIRAS, M. L.; CORREIA, L. G. (Coord.). Manuais Escolares da Biblioteca Pública Municipal do Porto. Porto: Faculdade de Psicologia e Ciências da Educação/ Faculdades de Letras do Porto, 2008. Disponível em: < http://repositorio. ul.pt/bitstream/10451/5958/1/O\%20manual\%20escolar $\% 20$ como $\% 20$ fonte $\% 20$ historiogr\%C3\%A1fica.pdf>. Acesso em: 10 set. 2014.

MANIFESTO dos pioneiros da educação nova (1932). Revista HISTEDBR On-line, Campinas, n. especial, p. 188-204, ago. 2006. Disponível em: <http://www. histedbr.fe.unicamp.br/revista/edicoes/22e/doc1_22e.pdf $>$. Acesso em: 05 set. 2014.

MENESES, U. B. A exposição museológica e o conhecimento histórico. In: FIGUEIREDO, B. G.; VIDAL, D. G. (Org.). Museus: dos gabinetes de curiosidade à museologia moderna. Belo Horizonte: Argvmentvm; Brasília: CNPq, 2005.

MENESES, U. B. Memória e cultura material: documentos pessoais no espaço público. Estudos Históricos, Rio de Janeiro, v. 11, n. 21, p. 89-103, 1998. Disponível em: < http://bibliotecadigital.fgv.br/ojs/index.php/reh/article/view\%20 File/2067/1206>. Acesso em: 17 ago. 2014.

NARCIZO, R. M. Ministro de Deus, portador da luz: ações e enunciados católicos de modelação docente na década de 1930. 2008. Dissertação (Mestrado em Educação)-Universidade do Estado do Rio de Janeiro, Rio de Janeiro, 2008. 
NUNES, C.; CARVALHO, M. M. C. Historiografia da educação e fontes. In: GONDRA, J. G. (Org.). Pesquisa em História da Educação no Brasil. Rio de Janeiro: DP\&A, 2005.

OSSENBACH SAUTER, G. Manuales escolares y patrimonio histórico-educativo. Educatio Siglo XXI, v. 28, n. 2, p. 115-132, 2010. Disponível em: <http://revistas. um.es/educatio/article/view/111991>. Acesso em: 07 ago. 2014.

ROCHA, H. H. P.; SOMOZA, M. Apresentação do dossiê Manuais escolares: múltiplas facetas de um objeto cultural. Pro-Posições, v. 23, n. 3. p. 21-31, set./dez. 2012. Disponível em: <http://www.scielo.br/scielo.php?pid=S0103$-73072012000300002 \&$ script $=$ sci_arttext $>$. Acesso em: 31 jul. 2014.

SANTA CATARINA (Estado). Decreto-Lei Estadual n. 298, de 18 de novembro de 1946. Expede a Lei Orgânica do Ensino Primário. Florianópolis: Imprensa Oficial do Estado, 1946.

SOUZA, R. F. História da cultura material escolar: um balanço inicial. In: BENCOSTTA, M. L. (Org.). Culturas escolares, saberes e práticas educativas: itinerários históricos. São Paulo: Cortez, 2007.

SOUZA, R. F. Preservação do patrimônio histórico escolar no Brasil: notas para um debate. Revista Linhas, Florianópolis, v. 14, n. 26, p. 199-221, jan./jun. 2013.

TEIVE, G. M. G. Caminhos teórico-metodológicos para a investigação de livros escolares: a contribuição do Centro de Investigación MANES. 2014. Revista Brasileira de Educação, v. 20, n. 63, p. 827-843, out./dez. 2015. Disponível em: <http:// www.scielo.br/pdf/rbedu/v20n63/1413-2478-rbedu-20-63-0827.pdf >. Acesso em: 05 dez. 2015.

VIÑAO FRAGO, A. Historia de la educación e historia cultural: Posibilidades, problemas, cuestiones. Revista Brasileira de Educação, v. 1, p. 63-82, set./dez. 1995.

Recebido em: 14 de fevereiro de 2016 Aceito em: 23 de maio de 2016

Endereço para correspondência: Gregório Francisco Ferreira, 19, Forquilhinhas, 88106-506, São José, Santa Catarina, Brasil; ma.marirosa@gmail.com 